\title{
Cytomorphology of Circulating Colorectal Tumor Cells: A Small Case Series
}

\author{
Dena Marrinucci, ${ }^{1}$ Kelly Bethel, ${ }^{2}$ Daniel Lazar, ${ }^{1}$ Jennifer Fisher, ${ }^{2}$ Edward Huynh, ${ }^{2}$ \\ Peter Clark, ${ }^{1}$ Richard Bruce, ${ }^{3}$ Jorge Nieva, ${ }^{4}$ and Peter Kuhn ${ }^{1}$ \\ ${ }^{1}$ Cell Biology Department, The Scripps Research Institute, 10550 North Torrey Pines Road, La Jolla, CA 92037, USA \\ ${ }^{2}$ Scripps Clinic Medical Group, Scripps Clinic, 10666 North Torrey Pines Road, La Jolla, CA 92037, USA \\ ${ }^{3}$ Scripps-PARC Institute for Advanced Biomedical Sciences, Palo Alto Research Center, 3333 Coyote Hill Road, Palo Alto CA, 94304, \\ USA \\ ${ }^{4}$ Oncology \& Hematology Department, Billings Clinic, 2825 Eighth Avenue North, Billings, MT 59107, USA
}

Correspondence should be addressed to Peter Kuhn, pkuhn@scripps.edu

Received 26 March 2009; Accepted 12 October 2009

Academic Editor: Sabine Kasimir-Bauer

Copyright (C) 2010 Dena Marrinucci et al. This is an open access article distributed under the Creative Commons Attribution License, which permits unrestricted use, distribution, and reproduction in any medium, provided the original work is properly cited.

\begin{abstract}
Several methodologies exist to enumerate circulating tumor cells (CTCs) from the blood of cancer patients; however, most methodologies lack high-resolution imaging, and thus, little is known about the cytomorphologic features of these cells. In this study of metastatic colorectal cancer patients, we used immunofluorescent staining with fiber-optic array scanning technology to identify CTCs, with subsequent Wright-Giemsa and Papanicolau staining. The CTCs were compared to the corresponding primary and metastatic tumors. The colorectal CTCs showed marked intrapatient pleomorphism. In comparison to the corresponding tissue biopsies, cells from all sites showed similar pleomorphism, demonstrating that colorectal CTCs retain the pleomorphism present in regions of solid growth. They also often retain particular cytomorphologic features present in the patient's primary and/or metastatic tumor tissue. This study provides an initial analysis of the cytomorphologic features of circulating colon cancer cells, providing a foundation for further investigation into the significance and metastatic potential of CTCs.
\end{abstract}

\section{Introduction}

The spread of cancer cells from the primary tumor site to distant organs results in an incurable condition associated with a high incidence of mortality [1]. Evidence indicates that primary tumor cells gain access to the bloodstream, thus becoming circulating tumor cells (CTCs) that travel via the peripheral blood to sites anatomically distant from the primary tumor. There they form secondary tumors, eventually producing lethal metastases, the major cause of treatment failure in cancer patients $[2,3]$.

Circulating epithelial cells (CEpiCs) have been detected in the peripheral blood of patients with a variety of metastatic epithelial malignancies at varying concentrations using several different methodologies [4-10]. In general, CEpiCs can be identified (using immunofluorescence assays) via monoclonal antibodies directed against epithelial-specific antigens, allowing them to be distinguished from normal blood cells $[11,12]$. In the setting of a patient with known metastatic carcinoma, these circulating epithelial cells are generally presumed to be circulating malignant tumor cells by most researchers in the field. Support for this presumption is emerging; research has demonstrated genomic changes of single CEpiCs and that the cells are aneuploid, suggestive evidence that these cells are indeed malignant [13-16]. For the purpose of this study, we use cytologic features of the CEpiCs and their correlation with the primary biopsies to support their presumed malignancy and henceforth in this report refer to these cells as CTCs.

The presence of CTCs has been shown to correlate with poor prognosis and lower survival in metastatic breast and colorectal cancer patients [17-20]. Limited pilot studies have also indicated the utility of detecting CTCs in metastatic colorectal patients although there is apparent 
discrepancy in enumeration among various studies $[4,20$, 21]. CTCs provide the link between the primary and metastatic tumors [22] so identification and characterization of CTCs holds promising implications for the detection and treatment management of metastatic epithelial malignancies. Furthermore, isolation and characterization of these cells will provide new insights on the biological mechanisms of metastasis.

Most CTC detection methods depend on immunomagnetic separation and immunofluorescent labeling of epithelial-specific antigens such as epithelial cell adhesion molecule (EpCam) and cytokeratin (CK); however, because of methodologic limitations, cytologic details of the cells are not discernible, and detailed morphologic studies and images of CTCs are limited [13, 22, 23]. Detailed description and images of the morphologic types of CTCs found specifically in metastatic colorectal patients are even more scant [23].

Much remains unknown about circulating tumor cells: how they enter the bloodstream, how frequently they are destroyed within the bloodstream, how they exit the bloodstream, and whether each CTC has the same metastatic potential, that is, the same potential for extravasation and development into a new tumor in a metastatic site [24]. Thus, mere enumeration of CTCs must be augmented by the ability to study individual cells by additional morphologic and/or molecular characterization that could provide clinically useful information as well as aid in our understanding of the metastatic process.

We have previously reported about an enrichment-free immunofluorescent staining protocol with fiber-optic array scanning technology (FAST) to enumerate and characterize CTCs found in metastatic cancer patients $[5,22,25]$. The methodology allows for detailed cytomorphologic analysis, and we have previously reported a detailed review of circulating breast carcinoma cells. We now add circulating colon cancer to the limited atlas of CTCs, with this small series in which we cytomorphologically evaluate CTCs from the blood of five metastatic colorectal cancer patients. Single cells found in the blood are also compared to archived histopathologic and cytologic specimens of the patient's primary and/or metastatic tumor.

\section{Materials and Methods}

2.1. Collection of Blood Samples. Five metastatic colorectal cancer patients provided informed consent at Scripps Clinic (La Jolla, CA) as approved by the Institutional Review Board. From each patient, $8 \mathrm{~mL}$ of peripheral blood was collected in a Rare Cell blood collection tube (Streck, Omaha, NE) and processed within 24 hours.

\subsection{Immunofluorescent Staining Protocol for Labeling CTCs.} Blood samples were subjected to an isotonic lysis with ammonium chloride buffer $\left(155 \mathrm{mM} \mathrm{NH}{ }_{4} \mathrm{Cl}, 10 \mathrm{mM}\right.$ $\mathrm{KHCO}_{3}, 0.1 \mathrm{mM}$ EDTA, pH 7.4). After 5 minutes on a rotator and a 5-minute centrifugation at $700 \mathrm{~g}$, the supernatant containing lysed red blood cells was removed. The resulting nucleated cell pellet was resuspended in phosphate buffered saline (PBS) and distributed on custom-designed adhesive slides (Marienfeld, Germany) that have an active area of $62 \mathrm{~cm}^{2}$ that can hold a monolayer of roughly 27 million nucleated cells. Slides were incubated at $37^{\circ} \mathrm{C}$ for 40 minutes. Cells were then fixed with $2 \%$ paraformaldehyde for 20 minutes, washed with PBS, and permeabilized with cold methanol for 5 minutes, followed by another PBS wash step. Subsequently, 10\% goat serum was added for 20 minutes to block nonspecific binding sites, followed by incubation at $37^{\circ} \mathrm{C}$ with monoclonal antipan cytokeratin (Sigma, MO) and conjugated CD45-Alexa647 (Serotec) antibodies for 40 minutes. After a PBS wash, the secondary antibody, Alexa555 (Invitrogen), was added for 20 minutes. Cells were counterstained with DAPI for 10 minutes and mounted with an aqueous mounting media.

2.3. FAST Scanning and ADM-Coupled Imaging of Immunofluorescently Labeled CTCs. Fiber-optic Array Scanning Technology (FAST) was used to identify the location of CTCs as described previously [25]. Briefly, an argon-ion laser excites fluorescence in labeled cells and determines the location of a fluorescently labeled cell by the scan and stage positions at the time of emission at a scan rate of 25 million cells per minute. Each FAST-identified object was then imaged with a $20 \mathrm{X}$ objective in fluorescence via automated digital microscopy (ADM).

2.4. Relocation of CTCs for Morphological Analysis. A pathologist used 20X magnification and applied strict criteria defining CTCs as cytokeratin positive, CD45 negative, and DAPI positive (nuclear stain). Enumeration of CTCs was done at 20X for all patient specimens. To morphologically evaluate fluorescent CTCs for further cytologic details, 100X images were taken. Subsequently, coverslips were removed and the Wright-Giemsa stain and/or Papanicolau stain was applied. Cells were then relocated using calibration fiducials and imaged in brightfield for further cytomorphologic analysis (Figure 1).

2.5. Patient Analysis. Primary and metastatic tumor biopsies were reviewed by a single pathologist. Architectural and cytologic features of each primary tumor and available metastatic tumor biopsies were reviewed. Patient status at the time of the blood draw (stable disease versus progressive disease) was determined by a blinded medical oncologist review of lab data including CEA, radiology, and clinician assessment of the patient around the time of draw.

\section{Results}

Patient and tumor characteristics are summarized in Table 1. Patients varied in the number and types of metastases as well as their line of therapy; however, review of the primary tumor slides demonstrated that all had presented with moderately differentiated adenocarcinoma. When primary tissue and metastatic tissue biopsies were available, all available tissue biopsies were examined. These 5 patients had detectable CTCs ranging from $12-282$ per $8 \mathrm{~mL}$ of blood. Although 


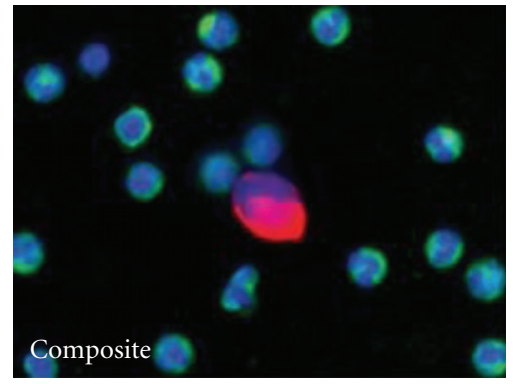

(a)

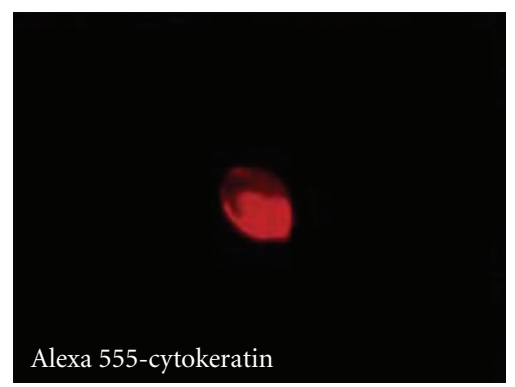

(c)

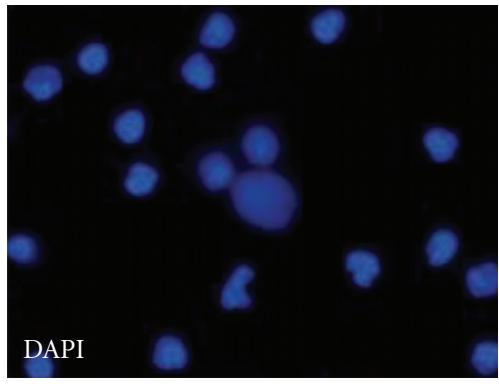

(b)

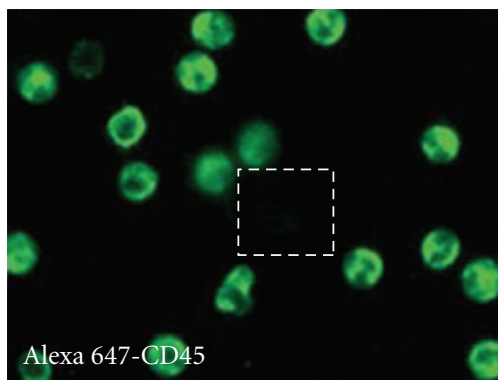

(d)

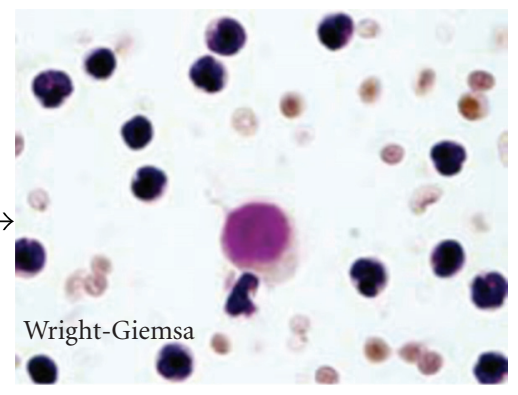

(e)

FIGURE 1: Relocation and characterization of CTCs using the Wright-Giemsa stain. After initial identification of CTCs via fluorescent images, subsequent Wright-Giemsa stain and/or Papanicolau stain of these cells is performed: (a) composite 3-color fluorescent image, (b) DAPI channel only, (c) cytokeratin channel only, (d) CD45 channel only, and (e) corresponding Wright-Giemsa-stained cell.

not a clinical outcomes study, we did note that patients who were identified as having progressive disease had significantly more cells than those patients who were stable at the time of the blood draw. Figure 2 shows representative CTCs found in each patient.

3.1. Detailed Cytomorphologic Evaluation of CTCs. In the peripheral blood, we found a markedly pleomorphic population of colon tumor cells as shown in the gallery of colorectal CTCs (Figure 3). There were not only large, high nuclear-to-cytoplasm (N/C) ratio cells (Figures 3(a) and $3(\mathrm{~g}))$ but also cells with moderate to voluminous amounts of cytoplasm, yielding moderate-to-low N/C ratios (Figures 3(e) and 3(f)). Overall CTC size also varied. Many were larger than the surrounding benign WBCs (Figures 3(a), $3(\mathrm{f})$, and $3(\mathrm{~g})$ ); however, there were also cells of the same size or smaller than surrounding WBCs (Figures 3(c), $3(\mathrm{~d})$, and 3(e)). In some cases, the smaller cells showed features suggestive of apoptosis, such as irregular nuclear or cytoplasmic condensation or frank fragmentation into dense rounded structures (Figure 3(e)).

Notable were frequent cells with irregular nuclear contours, either large lobations or fine irregularities (Figures $3(\mathrm{a})$ and 3(b)). Some of the nuclei with large lobations appeared monocytoid in shape, or showed a half moonlike configuration (Figure 3(f)); the nuclear invagination is occupied by cytokeratin-rich cytoplasm. In other cells, the nuclear irregularities are on a smaller scale, yielding a finely irregular nuclear contour to a generally round or oval nucleus (Figure 3(c)); these features are best demonstrated by high-powered examination of Papanicolau-stained cells at the microscope.

Eccentricity of the nuclear location within the cell cytoplasm is also a prominent feature in many of the circulating colon cancer cells. While the cytoplasm extends circumferentially around the nuclei, many cells show a cytoplasmic bulge on one side, occupied by cytokeratin-rich cytoplasm (Figures 3(c) and 3(d)). The corresponding Wright-Giemsa and Papanicolau-stained cells demonstrate a "plasmacytoid" appearance familiar to cytopathologists examining cytologic preparations of various adenocarcinomas.

\subsection{Detailed Architectural, Histologic, and Cytomorphologic} Review of Primary/Metastatic Tumor. All primary tumors in this small series were classified as moderately differentiated, with architectural features showing a predominance of abnormal gland formation and only focal areas of sheet-like growth. Figure 4 shows histology, cytology, and representative circulating tumor cells found in Patient E. This histology is representative of all patients in our series. The glandular lumens often contain necroinflammatory debris, the familiar "dirty necrosis" of colon cancer. The abnormal glands are formed by columnar cells with nuclear enlargement, hyperchromatism, elongation, and stratification. In some of the less well-differentiated glands, the tumor cells approach a cuboidal shape, but overall the predominant tumor cell shape is columnar. Individual cells vary in size; although most cells of the tumor are larger than any surrounding 

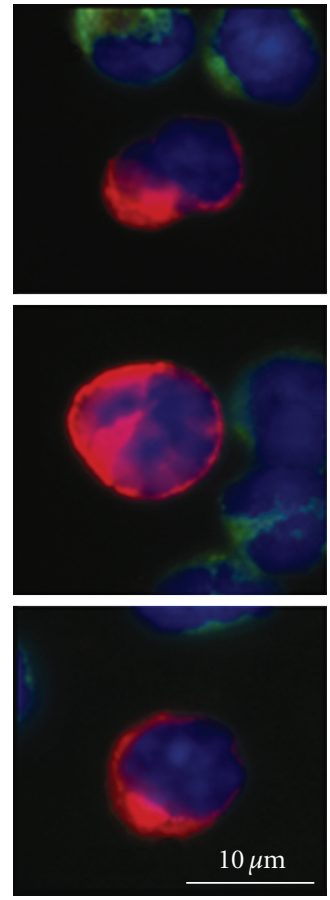

(a)
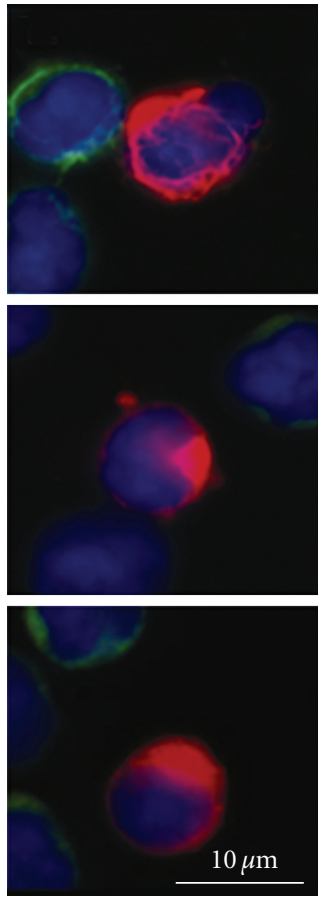

(b)
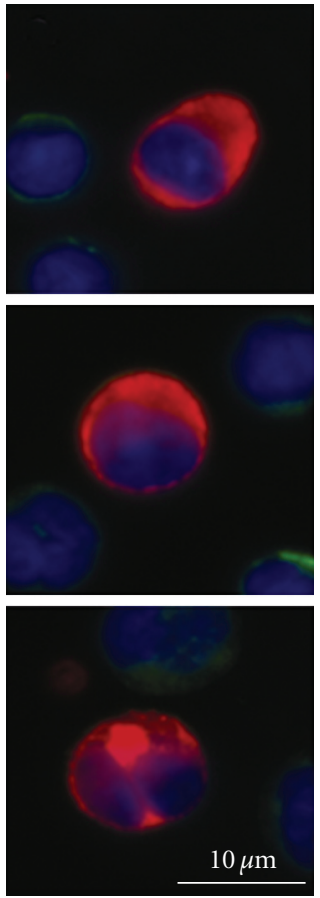

(c)
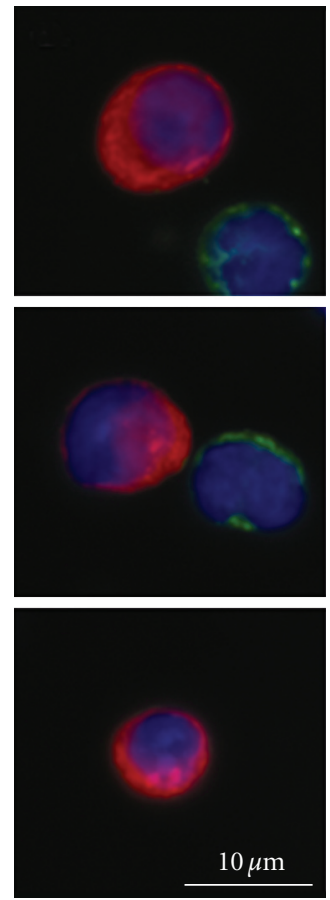

(d)
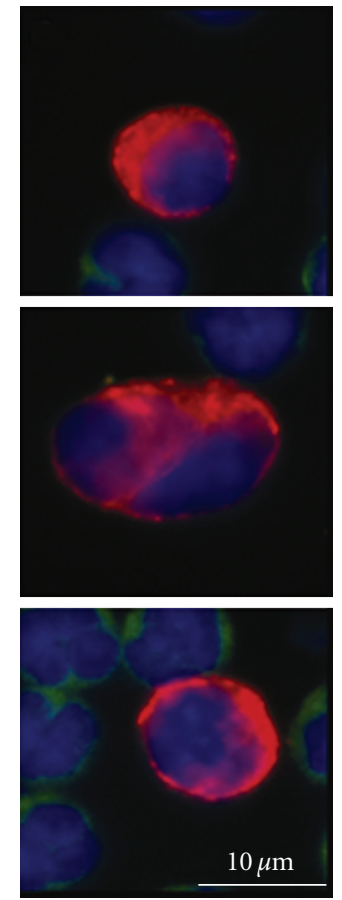

(e)

FIgure 2: Representative CTCs found in Patients 1-5. Each column represents one patient's CTCs: Red = cytokeratin, Green = CD45, and Blue $=$ DAPI .

TABLE 1: Patient tumor characteristics and circulating tumor cell count.

\begin{tabular}{|c|c|c|c|c|c|c|c|}
\hline Patient & Age/sex & $\begin{array}{c}\text { Time since } \\
\text { diagnosis } \\
\text { (mon) }\end{array}$ & Primary tumor site & $\begin{array}{l}\text { Location } \\
\text { of metastases }\end{array}$ & Line of therapy & CTCs (no. per $8 \mathrm{~mL}$ ) & Patient status \\
\hline Patient 1 & $60 / \mathrm{M}$ & 75 & Colon & $\begin{array}{l}\text { Liver, LN, lungs, } \\
\text { bone, paraspinal }\end{array}$ & 7 th & 282 & Progressive \\
\hline Patient 2 & $54 / \mathrm{M}$ & 37 & Colon & Liver & 4 th & 25 & Stable \\
\hline Patient 3 & $70 / \mathrm{F}$ & 27 & Colon & Liver & 1 st & 12 & Stable \\
\hline Patient 4 & $44 / \mathrm{F}$ & 16 & Rectum & $\begin{array}{l}\text { Liver, lungs, LN } \\
\text { ovaries, } \\
\text { retroperitoneum }\end{array}$ & $1 \mathrm{st}$ & 23 & Stable \\
\hline Patient 5 & $66 / \mathrm{F}$ & 87 & Colon & $\begin{array}{l}\text { Liver, retroperitoneal, } \\
\text { lung, endometrium }\end{array}$ & 9th & 164 & Progressive \\
\hline
\end{tabular}

benign cells, there is a marked range of cell size within the tumor, and cells at the smaller range of cell size approach that of neighboring histiocytes or other benign stromal cells. $\mathrm{N} / \mathrm{C}$ ratio is also quite variable within the tumor cell population; while high N/C ratio cells are certainly present, there are also abundant cells with moderate-to-low $\mathrm{N} / \mathrm{C}$ ratios due to their voluminous cytoplasmic domain. Individual tumor nuclei also frequently show nuclear lobation, and/or fine nuclear irregularities, features more easily appreciated in the cytology specimens from fine needle biopsies of metastases (Figure 4). Apoptotic or degenerating individual tumor cells are frequently observed, as are mitotic figures.
3.3. Cytomorphologic Comparison of CTCs to the Primary and Metastatic Tumors. In comparison to the tissue biopsies from both primary and metastatic tumor sites, the morphologic cell mix of circulating colon tumor cells is similar in its pleomorphism. Certain cytologic features noted in the tissue biopsies, in particular prominent lobation of nuclear contours, are clearly evident in the circulating population. As well, fine irregularity of nuclear membrane contours noted in solid tissue samples persists in the circulating population of tumor cells. Finally, colon tumor cells in circulation show a morphologic tendency toward eccentricity of the cytokeratin-rich cytoplasm, while their solid tissue counterparts appear columnar in shape. 


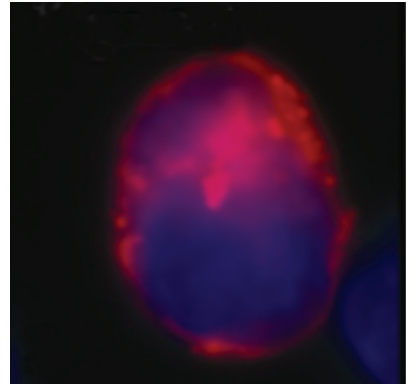

(a)
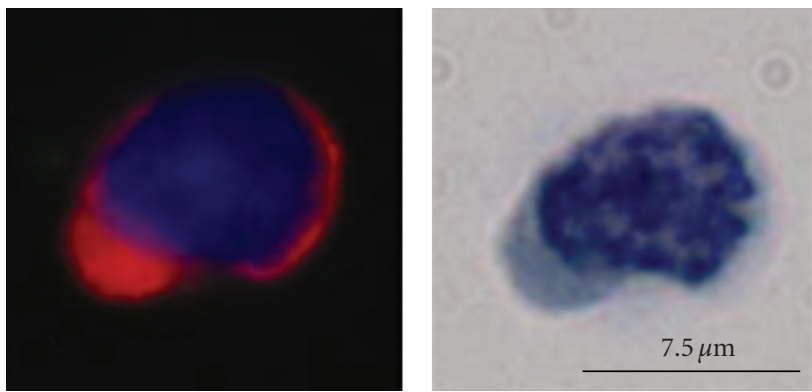

(c)
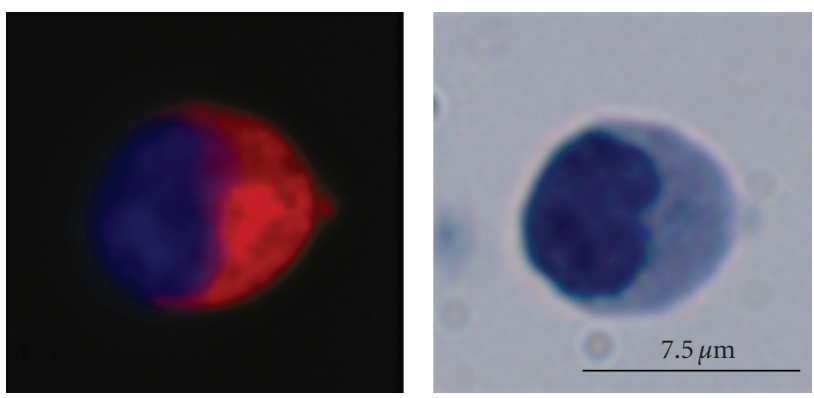

(e)
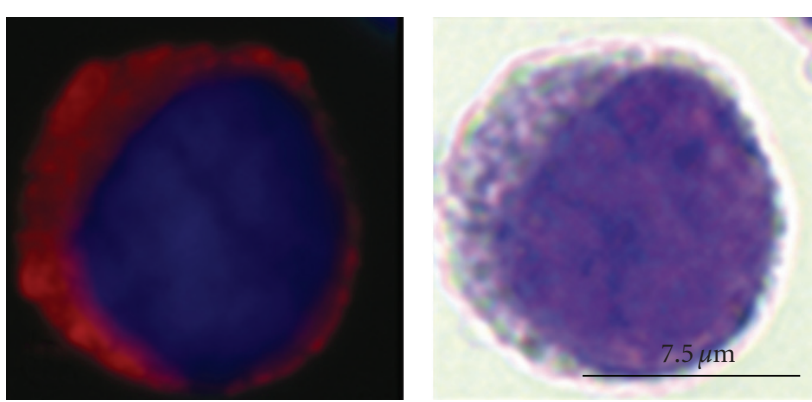

(g)

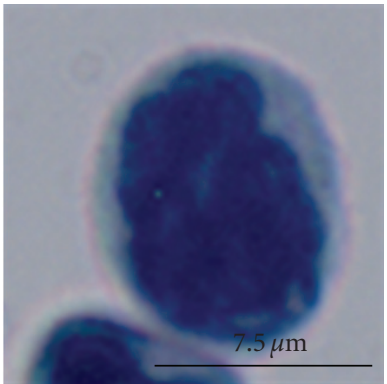

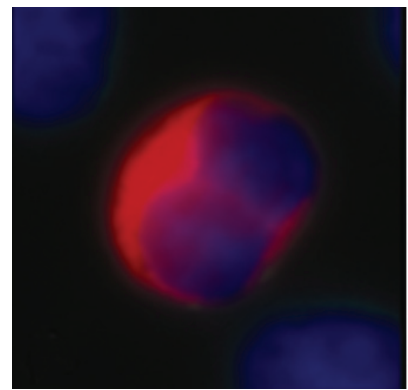

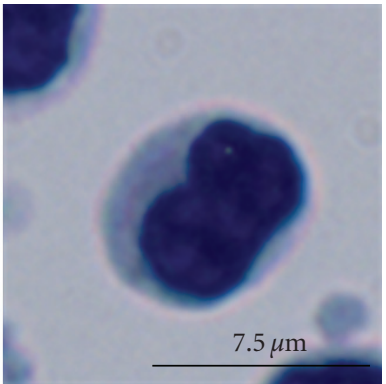

(b)
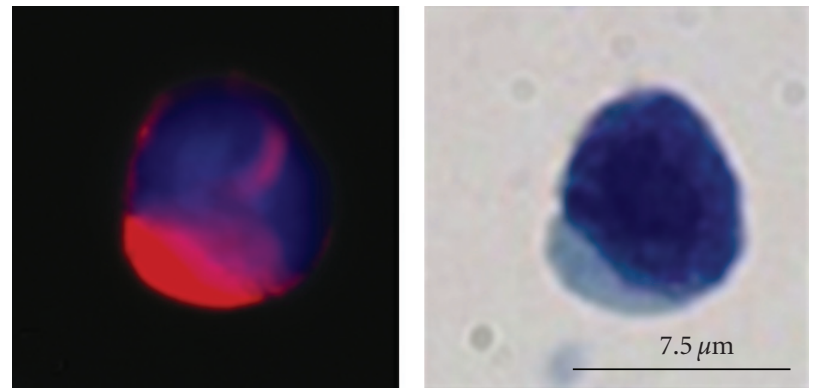

(d)
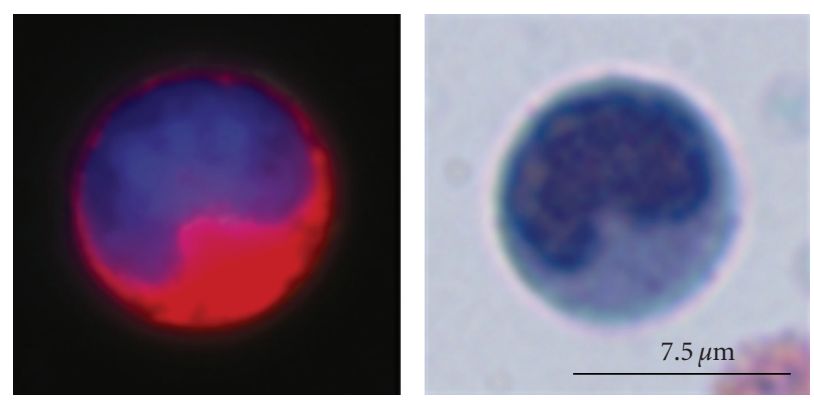

(f)
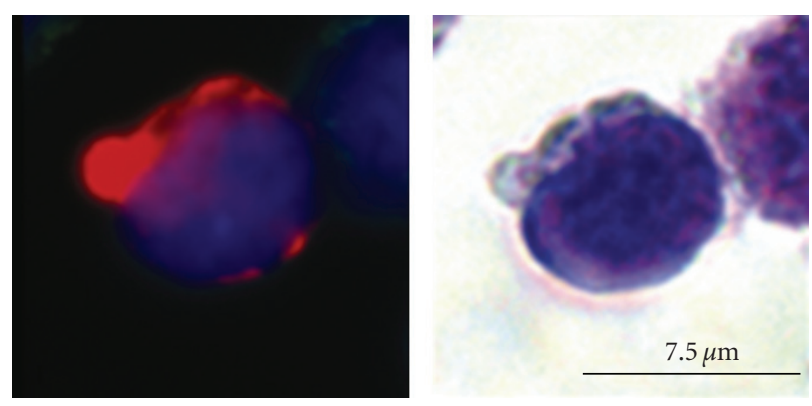

(h)

FIgURE 3: CTCs pleomorphism in the blood of metastatic colorectal patients using fluorescent, Papanicolau, and Wright-Giemsa stains. Representative types of CTCs identified in patient cohort. Left: fluorescent-stained CTC; Red: Alexa555-cytokeratin, Green: Alexa 647CD45, and Blue: DAPI. (a)-(f) Right: corresponding CTC viewed with Papanicolau stain. (g), (h) Right: corresponding CTC viewed with Wright-Giemsa stain.

\section{Discussion}

Comparison of primary and metastatic colon tumor cells to circulating colorectal tumor cells shows marked congruence of cytologic features between the tissue compartments as illustrated in Figures 2-4. Histopathologically, these tumors are moderately differentiated adenocarcinomas, with columnar tumor cells forming abnormal glands; the nuclei are irregularly contoured and frequently lobated. Cytologically, the primary and metastatic tumor deposits show pleomorphism among the individual cells of the tumor tissue. Circulating cells from these same patients retain 


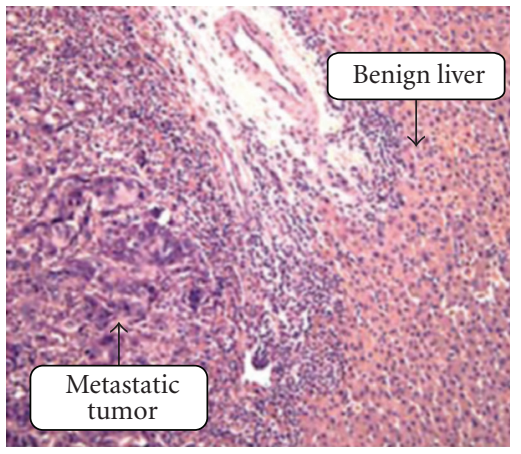

(a)

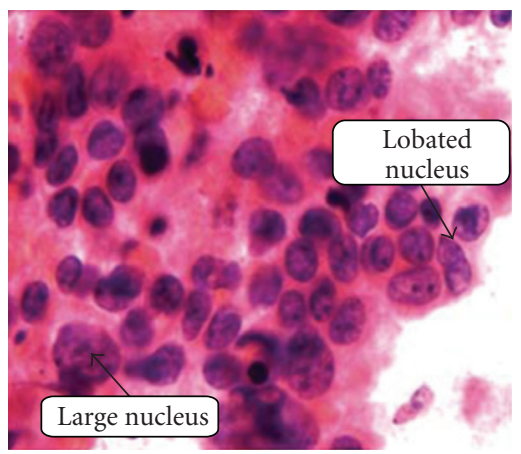

(c)

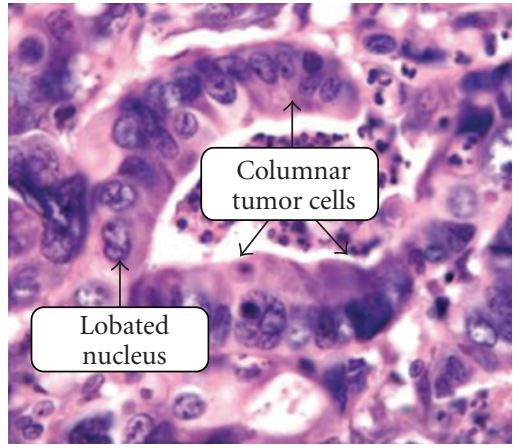

(b)

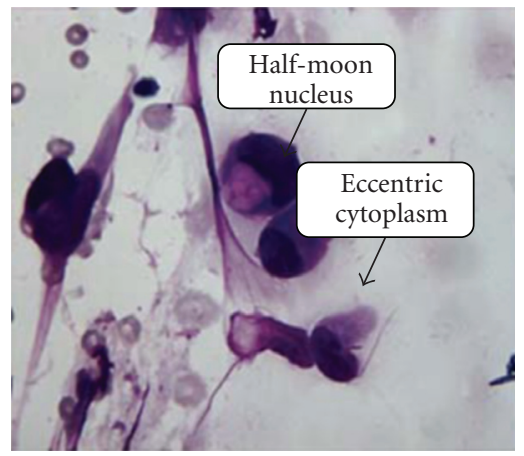

(d)

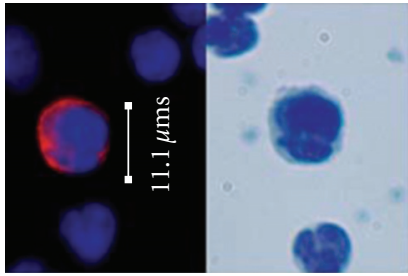

(e)

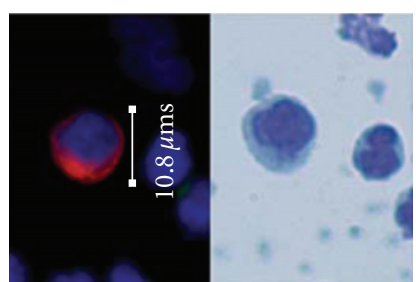

(f)

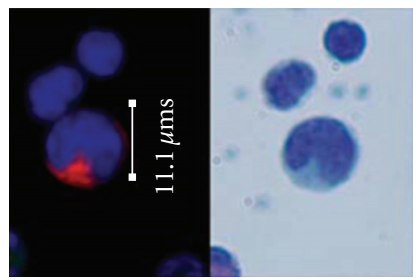

(g)

FIGURE 4: Comparison of CTC morphology with biopsy histology and touch preparation cytology in a patient with metastatic colorectal cancer. (a) Low-power histology of the liver metastasis from 1999 of Patient E (H \& E, 20X). (b) High-power histology of the liver metastasis from 1999 of Patient E (H \& E, 110X oil). (c) High-power cytology of retroperitoneal metastasis from 2002 of Patient E (H\&E Stain, 100X oil). (d) High-power cytology of retroperitoneal metastasis from 2002 of Patient E (Wright-Giemsa stain, 100X oil). (e)-(g) CTCs identified in the blood of Patient E in 2008.

this cytomorphology, showing overall pleomorphism with variations in size, shape, and N/C ratios as well. The CTCs show nuclear contour irregularity and lobation, with eccentrically located cytoplasm corresponding to a columnar-type adenocarcinoma cell. This analysis supports the premises that CTCs retain primary tumor cytologic characteristics and that CTCs represent a random sampling of the many phenotypic cell types present in the primary and metastatic tumor deposits. The findings argue against the theory that only particular subsets of tumor cells enter the peripheral blood, such as very poorly differentiated "stem cell"-like tumor cells, or only visibly dead/dying apoptotic tumor cells. The findings support the possibility that circulating tumor cells consist of a combination of passively "shed" cells with little malignant potential and actively "migrating" cells that are viable and may go on to form further metastatic foci [26].

In comparison to a previous morphologic study of CTCs in breast cancer, the pleomorphism in the circulating population of colorectal cancer is similar to the pleomorphism in the circulating population in breast cancer. However, there appear to be subtle, but appreciable cytologic differences between the two cancer types; the circulating breast cancer cells are generally round with circumferential cytoplasm, while many of the circulating colon cancer cells appear eccentric, with a cytoplasmic bulge on one side. The subtle differences in shape between CTCs of the two tumor types are felt likely to be a result of the cell shape of the original tumor type. The cells of breast cancer are usually cuboidal rather than columnar, and the corresponding detached CTCs show evenly distributed cytoplasm with no discernible eccentricity. One can theorize that the more exaggerated the columnar shape and/or basally oriented nuclei of the original tumor cells, the more eccentric the cytoplasm will appear when the cell detaches from the stroma and enters the circulation. Future evaluation of additional cases of adenocarcinoma where the primary tumor is either very well differentiated or very poorly differentiated will serve to further address this connection between the appearance of the cells in tissue versus that in circulation.

Morphologic evaluation of the characteristics of circulating tumor cells from different malignancies including patients with nonmetastatic disease will contribute to our future understanding of the metastatic process. Furthermore, as CTC enumeration and characterization enter the mainstream of cancer diagnostics and care, familiarity with the appearance and variability of features of CTCs will be important for pathologists. This small series demonstrates that colon cancer cells in circulation are not dissimilar in appearance from the cells in tissue within a single patient, and that between tumor types, the cells in circulation may 
vary in their appearance. As new techniques for further assessment of the circulating component of epithelial tumors emerge, these cells may serve as an easily accessible real-time 'biopsy' of the active tumor in a patient's body.

\section{Acknowledgments}

The authors thank the research nursing staff at Scripps Clinic, La Jolla, for consenting patients and collecting blood specimens. They also thank Chris Rombaoa for the Papanicolau staining and Elvia Nunez for manuscript preparation. This work was supported by the Hematology Oncology Fellowship at Scripps Green Hospital/Scripps Clinic Medical Group to JF and EH , private donations to the Kuhn Laboratory, the Wayne Green fellowship and ARCS fellowship to DM, and NIH NCI Grants CA111359 and CA125653. This is TSRI Manuscript number 20270.

\section{References}

[1] S. A. Eccles and D. R. Welch, "Metastasis: recent discoveries and novel treatment strategies," The Lancet, vol. 369, no. 9574, pp. 1742-1757, 2007.

[2] J. L. Townson, G. N. Naumov, and A. F. Chambers, "The role of apoptosis in tumor progression and metastasis," Current Molecular Medicine, vol. 3, no. 7, pp. 631-642, 2003.

[3] S. Braun, B. S. Cevatli, C. Assemi, et al., "Comparative analysis of micrometastasis to the bone marrow and lymph nodes of node-negative breast cancer patients receiving no adjuvant therapy," Journal of Clinical Oncology, vol. 19, no. 5, pp. 14681475, 2001.

[4] W. J. Allard, J. Matera, M. C. Miller, et al., "Tumor cells circulate in the peripheral blood of all major carcinomas but not in healthy subjects or patients with nonmalignant diseases," Clinical Cancer Research, vol. 10, no. 20, pp. 68976904, 2004.

[5] H. B. Hsieh, D. Marrinucci, K. Bethel, et al., "High speed detection of circulating tumor cells," Biosensors and Bioelectronics, vol. 21, no. 10, pp. 1893-1899, 2006.

[6] S. Nagrath, L. V. Sequist, S. Maheswaran, et al., "Isolation of rare circulating tumour cells in cancer patients by microchip technology," Nature, vol. 450, no. 7173, pp. 1235-1239, 2007.

[7] K. Pachmann, O. Camara, A. Kavallaris, et al., "Monitoring the response of circulating epithelial tumor cells to adjuvant chemotherapy in breast cancer allows detection of patients at risk of early relapse," Journal of Clinical Oncology, vol. 26, no. 8, pp. 1208-1215, 2008.

[8] S. Riethdorf, H. Fritsche, V. Müller, et al., "Detection of circulating tumor cells in peripheral blood of patients with metastatic breast cancer: a validation study of the cell search system," Clinical Cancer Research, vol. 13, no. 3, pp. 920-928, 2007.

[9] D. R. Shaffer, M. A. Leversha, D. C. Danila, et al., "Circulating tumor cell analysis in patients with progressive castrationresistant prostate cancer," Clinical Cancer Research, vol. 13, no. 7, pp. 2023-2029, 2007.

[10] S. J. Cohen, R. K. Alpaugh, S. Gross, et al., "Isolation and characterization of circulating tumor cells in patients with metastatic colorectal cancer," Clinical Colorectal Cancer, vol. 6, no. 2, pp. 125-132, 2006.

[11] R. Moll, "Cytokeratins as markers of differentiation in the diagnosis of epithelial tumors," Sub-Cellular Biochemistry, vol. 31, pp. 205-262, 1998.
[12] K. Pantel, G. Schlimok, M. Angstwurm, et al., "Methodological analysis of immunocytochemical screening for disseminated epithelial tumor cells in bone marrow," Journal of Hematotherapy, vol. 3, no. 3, pp. 165-173, 1994.

[13] T. Fehm, A. Sagalowsky, E. Clifford, et al., "Cytogenetic evidence that circulating epithelial cells in patients with carcinoma are malignant," Clinical Cancer Research, vol. 8, no. 7, pp. 2073-2084, 2002.

[14] J. A. Schardt, M. Meyer, C. H. Hartmann, et al., "Genomic analysis of single cytokeratin-positive cells from bone marrow reveals early mutational events in breast cancer," Cancer Cell, vol. 8, no. 3, pp. 227-239, 2005.

[15] R. Gangnus, S. Langer, E. Breit, K. Pantel, and M. R. Speicher, "Genomic profiling of viable and proliferative micrometastatic cells from early-stage breast cancer patients," Clinical Cancer Research, vol. 10, no. 10, pp. 3457-3464, 2004.

[16] S. Maheswaran, L. V. Sequist, S. Nagrath, et al., "Detection of mutations in EGFR in circulating lung-cancer cells," The New England Journal of Medicine, vol. 359, no. 4, pp. 366-377, 2008.

[17] M. Cristofanilli, G. T. Budd, M. J. Ellis, et al., "Circulating tumor cells, disease progression, and survival in metastatic breast cancer," The New England Journal of Medicine, vol. 351, no. 8, pp. 781-791, 2004.

[18] M. Cristofanilli, D. F. Hayes, G. T. Budd, et al., "Circulating tumor cells: a novel prognostic factor for newly diagnosed metastatic breast cancer," Journal of Clinical Oncology, vol. 23, no. 7, pp. 1420-1430, 2005.

[19] J.-Y. Pierga, C. Bonneton, A. Vincent-Salomon, et al., "Clinical significance of immunocytochemical detection of tumor cells using digital microscopy in peripheral blood and bone marrow of breast cancer patients," Clinical Cancer Research, vol. 10, no. 4, pp. 1392-1400, 2004.

[20] S. J. Cohen, C. J. A. Punt, N. Iannotti, et al., "Relationship of circulating tumor cells to tumor response, progressionfree survival, and overall survival in patients with metastatic colorectal cancer," Journal of Clinical Oncology, vol. 26, no. 19, pp. 3213-3221, 2008.

[21] J. Sastre, M. L. Maestro, J. Puente, et al., "Circulating tumor cells in colorectal cancer: correlation with clinical and pathological variables," Annals of Oncology, vol. 19, no. 5, pp. 935-938, 2008.

[22] D. Marrinucci, K. Bethel, R. H. Bruce, et al., "Case study of the morphologic variation of circulating tumor cells," Human Pathology, vol. 38, no. 3, pp. 514-519, 2007.

[23] B. Molnar, A. Ladanyi, L. Tanko, L. Sréter, and Z. Tulassay, "Circulating tumor cell clusters in the peripheral blood of colorectal cancer patients," Clinical Cancer Research, vol. 7, no. 12, pp. 4080-4085, 2001.

[24] K. Pantel, R. H. Brakenhoff, and B. Brandt, "Detection, clinical relevance and specific biological properties of disseminating tumour cells," Nature Reviews Cancer, vol. 8, no. 5, pp. 329340, 2008.

[25] R. T. Krivacic, A. Ladanyi, D. N. Curry, et al., "A rare-cell detector for cancer," Proceedings of the National Academy of Sciences of the United States of America, vol. 101, no. 29, pp. 10501-10504, 2004.

[26] M. Bockhorn, R. K. Jain, and L. L. Munn, "Active versus passive mechanisms in metastasis: do cancer cells crawl into vessels, or are they pushed?" The Lancet Oncology, vol. 8, no. 5, pp. 444-448, 2007. 


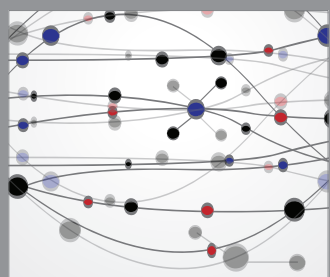

The Scientific World Journal
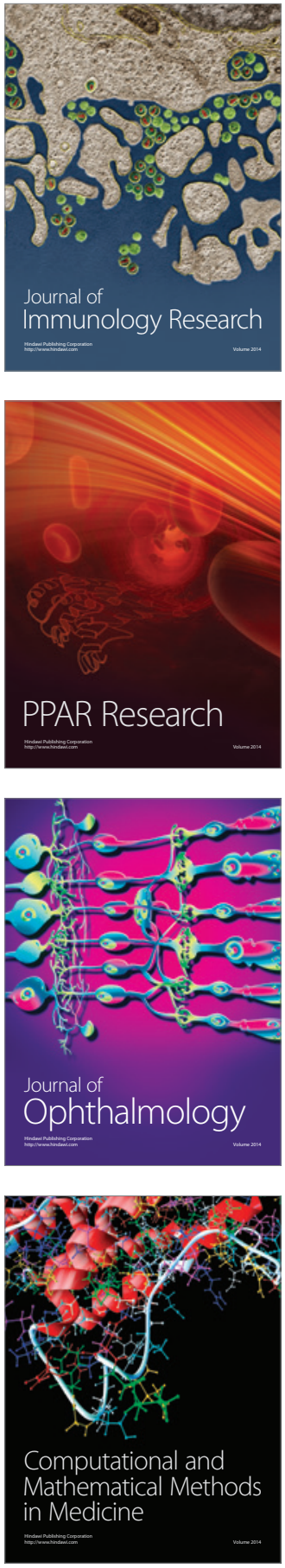

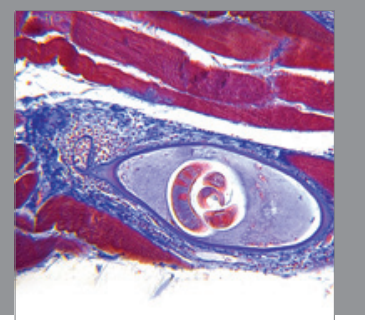

Gastroenterology

Research and Practice
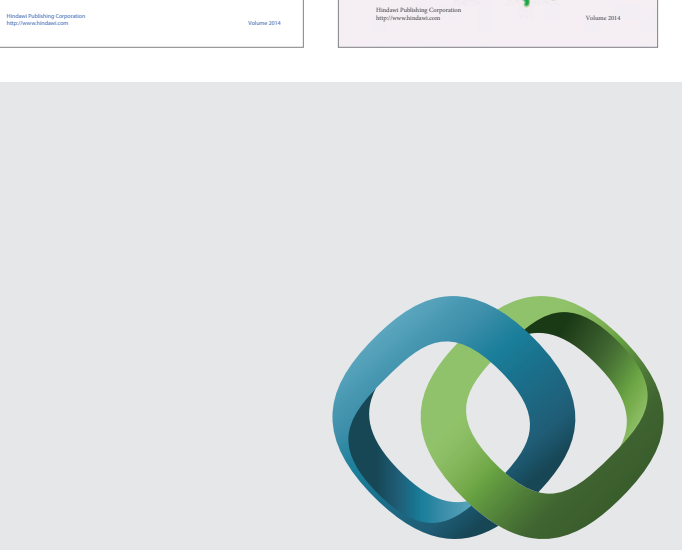

\section{Hindawi}

Submit your manuscripts at

http://www.hindawi.com
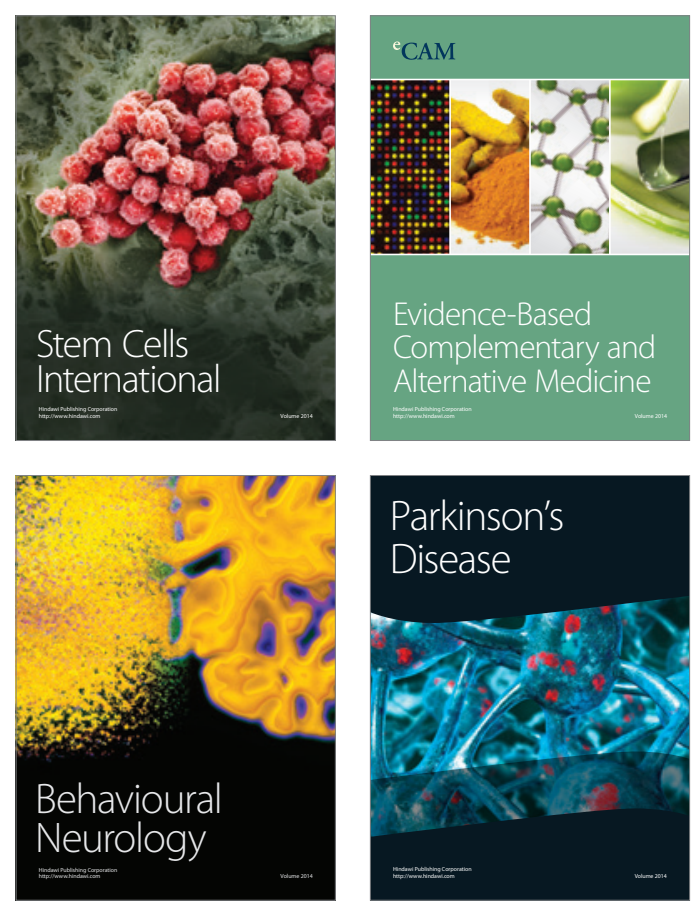

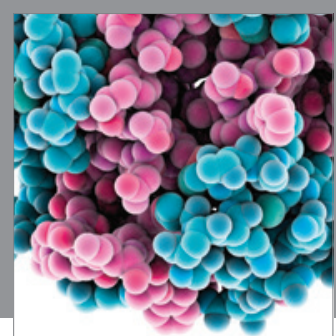

Journal of
Diabetes Research

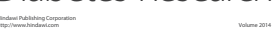

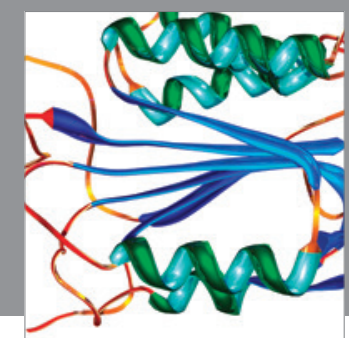

Disease Markers
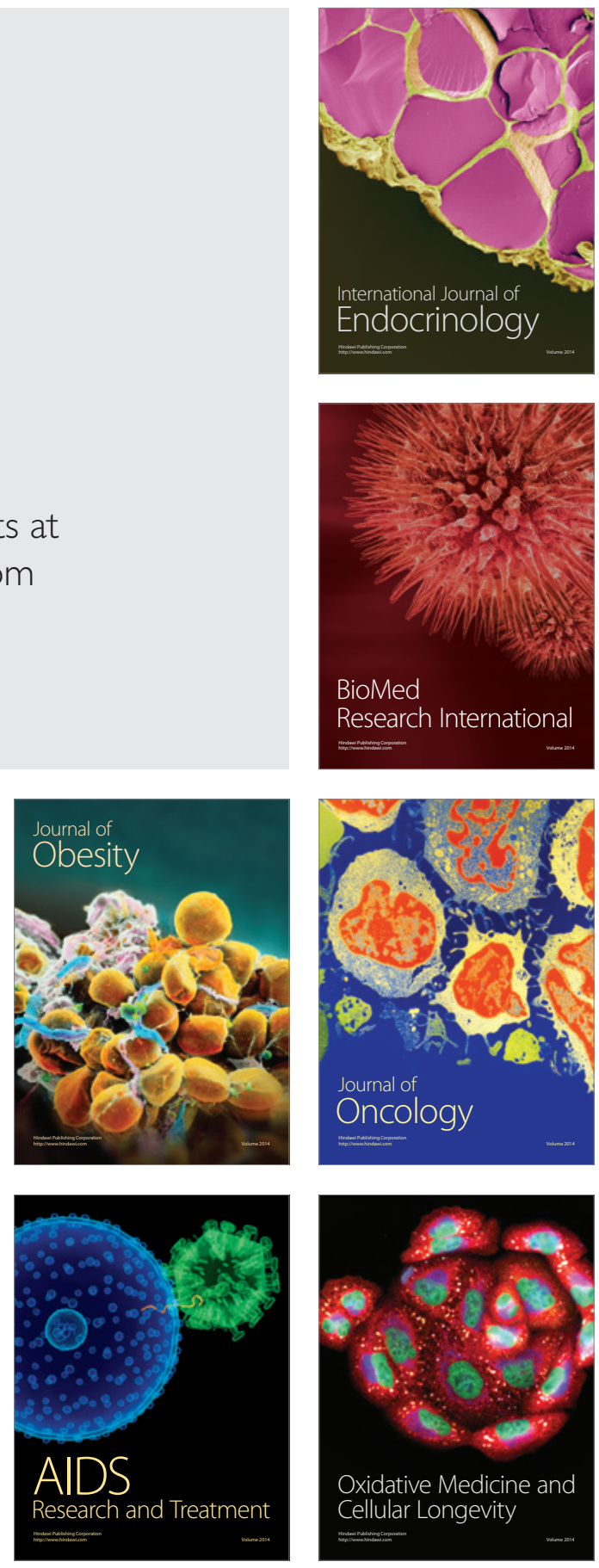